\title{
Biological Control of Botrytis cinerea: Interactions with Native Vineyard Yeasts from Washington State
}

\author{
Xuefei Wang, Dean A. Glawe, Elizabeth Kramer, David Weller,† and Patricia A. Okubara ${ }^{\dagger}$
}

First, second, and third authors: Department of Plant Pathology, Washington State University, Pullman 99164-6430; and fourth and fifth authors: United States Department of Agriculture-Agricultural Research Service Wheat Health, Genetics and Quality Research Unit, Pullman, WA 99164-6430.

Accepted for publication 10 January 2018.

\begin{abstract}
Native yeasts are of increasing interest to researchers, grape growers, and vintners because of their potential for biocontrol activity and their contributions to the aroma, flavor, and mouthfeel qualities of wines. To assess biocontrol activity, we tested 11 yeasts from Washington vineyards, representing isolates of Candida saitoana, Curvibasidium pallidicorallinum, Metschnikowia chrysoperlae, M. pulcherrima, Meyerozyma guilliermondii, Saccharomyces cerevisiae, and Wickerhamomyces anomalus, for ability to colonize Thompson Seedless grape berries, inhibit the growth of Botrytis cinerea in vitro, and suppress disease symptoms on isolated berries. The yeast-like fungus Aureobasidium pullulans was also included based on its known biocontrol activity against $B$. cinerea in studies on apple and grape. All yeast strains multiplied rapidly in grape berries and reached densities of over $\log 6$ cells per wound as early as 2 days after inoculation with 200

multilocus sequence analysis. Suppression of the growth of $B$. cinerea isolates $111 \mathrm{bb}, 207 \mathrm{a}, 207 \mathrm{cb}$, and $407 \mathrm{cb}$ occurred on berries treated with $A$. pullulans P01A006, Metschnikowia chrysoperlae P34A004 and P40A002, M. pulcherrima $\mathrm{P} 01 \mathrm{~A} 016$ and $\mathrm{P} 01 \mathrm{C} 004$, Meyerozyma guilliermondii P34D003, and S. cerevisiae HNN11516. Inhibition of Botrytis isolates by the yeast strains was more common on berries than in vitro, suggesting the possibility that niche competition was a more likely biocontrol mechanism than antibiosis in planta. Metabolic profiling of yeast strains and B. cinerea isolates using Biolog YT plates revealed seven distinct metabolic groups. Furthermore, the yeast strains showed partial to complete tolerance to the commonly used fungicides fluopyram, triflumizole, metrafenone, pyraclostrobin, and boscalid. Implications of these findings for field deployment of native Washington yeasts as biocontrol agents against $B$. cinerea are discussed.
\end{abstract} cells. One of the Botrytis isolates used in this study was much less virulent than the others and was provisionally identified as B. prunorum based on
Additional keywords: Botrytis bunch rot, gray mold, postharvest disease.
The state of Washington is the second largest producer of premium wines in the United States and is among the world's top wine grapegrowing regions (WASS 2003). Most cultivars of grape are highly susceptible to Botrytis bunch rot (also called gray mold), which causes a destructive decay of vineyard grape and postharvest decay of table grape. The disease is most severe under cool, wet growing conditions but is a problem throughout the world (Elmer and Reglinski 2006; Steel et al. 2013). In 2010, a Botrytis bunch rot epidemic affected approximately 4,900 ha of wine grape in central Washington, leading to losses of $\$ 17$ million (Moyer and Grove 2011).

The causal agent of Botrytis bunch rot, Botrytis cinerea, is a natural component of the vineyard microbiota (Steel et al. 2013); wounds or openings in host surfaces serve as infection courts. The pathogen can be very active during postharvest storage, even under strictly managed storage conditions (Keller et al. 2003). Latent infections were found to occur at a rate of approximately $0.5 \%$ in south-central Washington (Dugan et al. 2002). The fungus detracts from wine quality by producing laccases during fermentation, leading to tissue browning and discoloration of both white and red wines (Van Rensburg and Pretorius 2000).

${ }^{\dagger}$ Corresponding authors: P. A. Okubara: E-mail: patricia.okubara@ars.usda.gov; and D. M. Weller: E-mail: david.weller@ars.usda.gov

Funding: This research was funded by the China Scholarship Council (to X. Wang) and Grant 3061-5313 from the Washington State Grape and Wine Research Program (to P. A. Okubara)

*The $\boldsymbol{e}$-Xtra logo stands for "electronic extra" and indicates that three supplementary figures are published online.

This article is in the public domain and not copyrightable. It may be freely reprinted with customary crediting of the source. The American Phytopathological Society, 2018.
Management of Botrytis bunch rot continues to be a challenge for growers, winemakers, and table grape distributors. Grapevine canopy management, use of grape clones with loose cluster architecture, and application of fungicides are recommended management practices in Washington State (Moyer and Grove 2011). Because there are no highly resistant or tolerant commercial cultivars (Wilcox et al. 2015), application of synthetic fungicides has been the method of choice to manage Botrytis bunch rot for the last 60 years (Rosslenbroich and Stuebler 2000; Smilanick et al. 2010). Unfortunately, fungicides can cause problems such as bleaching injury, adulteration of wine flavor, sulfur allergies, environmental issues, and fungicide resistance among pathogens (Calvo-Garrido et al. 2014; Sanzani et al. 2012). In addition, fungicide residues on berries can influence the performance of yeasts during fermentation, and are regulated for use on table grape (Cabras and Angioni 2000).

Biological control is an attractive alternative to fungicides for the control of Botrytis bunch rot (Janisiewicz and Korsten 2002; Zhimo et al. 2014). Native (also called wild, "naturally occurring", or indigenous) grape-associated microbes are specifically adapted to the berry ecosystem (Janisiewicz and Korsten 2002; Parafati et al. 2015), and native yeasts have been shown to suppress the growth of $B$. cinerea from grape and apple in the laboratory (Dugan et al. 2002; Liu et al. 2010; Masih et al. 2000; Spadaro et al. 2002). Native yeasts are attractive as biocontrol agents of fruit disease due to their simple nutritional requirements, stability during storage, and ability to rapidly colonize pathogen infection courts (Chanchaichaovivat et al. 2007). Commercial biofungicides based on six species of native yeasts have been developed for postharvest control of $B$. cinerea of citrus and pome fruit (Spadaro and Droby 2016).

The objective of this study was to characterize Botrytis isolates obtained from grape berries grown in Washington vineyards, and 
the biocontrol activities of native yeasts against these isolates. A previous survey of native yeasts on grape in a vineyard in central Washington identified over 50 species representing 16 genera (Bourret et al. 2013). Several of these yeast species are known to contribute to the aroma, flavor, and mouthfeel qualities of Washington wines (Jolly et al. 2006). These yeast species also inhibited B. cinerea in laboratory assays (Kramer 2015). For the present study, we selected 11 yeast strains with promising inhibitory activity against $B$. cinerea, and expanded our studies to Washington isolates of $B$. cinerea. As detailed herein, this study suggests that native yeasts exhibit biocontrol potential for use against $B$. cinerea in Washington but the amount of activity varies with the isolate of the pathogen.

\section{MATERIALS AND METHODS}

Native yeasts, $B$. cinerea, and grape cultivars used in this study. Eleven strains of native yeasts and nine isolates of $B$. cinerea were used in this study (Table 1). The yeast-like fungus Aureobasidium pullulans was included based on its well-documented biocontrol activity against $B$. cinerea (Castoria et al. 2001; Dugan et al. 2002; Vero et al. 2009). All of the non-Saccharomyces yeasts were isolated from wine grape in a research vineyard at the Washington State University Irrigated Agriculture Research and Extension Center, Prosser (Bourret et al. 2013). Saccharomyces cerevisiae HNN11516 was isolated from a native fermentation in the lab. Yeast strains were maintained on potato dextrose agar (PDA) (Becton Dickinson, Franklin Lakes, NJ) or Wallerstein Laboratory Nutrient Medium agar (WLNA) (Becton Dickinson). Yeast strains were stored in $30 \%$ glycerol at $-80^{\circ} \mathrm{C}$. Nine $B$. cinerea isolates, initially identified on the basis of cultural and morphological criteria, were collected from grapevine buds or berries at a vineyard in Prosser, WA (Dugan et al. 2002) and further identified in this study as described below. In 2015, the isolates were recovered from silica gel and single-spore isolates were established. The Botrytis isolates were routinely cultured on half-strength (1/2) V8 agar (10\% V8 juice, 2\% agar, and $0.15 \%$ $\left.\mathrm{CaCO}_{3}\right)($ Stevens 1981$)$ and grown at $24^{\circ} \mathrm{C}$ under a 12 -h photoperiod. Isolates were archived on 1.5-cm-diameter discs of sterile filter paper in autoclaved envelopes. Filter paper discs were placed on an agar plate of an isolate and the fungus was allowed to grow over the paper.
After drying overnight under a stream of sterile air, the paper discs were placed in envelopes and stored at $-20^{\circ} \mathrm{C}$.

The growth rates of the Botrytis isolates were quantified on $1 / 2$ V8 agar. For each isolate, a 4-mm-plug of inoculum was placed at the center of a Petri plate and incubated at $24^{\circ} \mathrm{C}$. The colony radius was measured from the center of the plug to the leading edge of the colony every $12 \mathrm{~h}$ for up to $96 \mathrm{~h}$. Each treatment (isolate) was replicated four times, with a single plate serving as a replicate. The experiment was conducted twice, the data were pooled, and the area under the growth curve (AUGC) was calculated. The colony morphology of each isolate was determined on acidified PDA (APDA), King's medium B (KMB), and pea agar medium (PAM) after 7 days of incubation at $20^{\circ} \mathrm{C}$ with a cycle of $12 \mathrm{~h}$ of light and $12 \mathrm{~h}$ of darkness, as described by Ferrada et al. (2016).

Grape berries of the cultivar Thompson Seedless (Vitis vinifera L.), purchased from a local grocery store, were used for Botrytis virulence tests and in vivo biological control studies.

Molecular characterization of Botrytis strains. Sequences of the internal transcribed spacer (ITS) region of the nuclear ribosomal DNA and partial sequences of the glyceraldehyde-3-phosphate dehydrogenase (G3PDH) and heat-shock protein60 (HSP60) genes were obtained to confirm generic assignment and species identity of the Botrytis isolates. B. cinerea isolates were cultured on 1/2 V8 agar for $48 \mathrm{~h}$. Mycelia were collected and washed once in sterile water. Genomic DNA was extracted from fungal cultures grown for $48 \mathrm{~h}$ using a FastDNA SPIN KIT (MP Biomedicals, Solon, OH). Sequences encoding the $5.8 \mathrm{~S}$ ribosomal RNA and the adjacent ITS1 and ITS2 regions were amplified using primers ITS1 and ITS4 (White et al. 1990). Polymerase chain reaction (PCR) primers to amplify the portions of the G3PDH and HSP60 genes were described previously by Staats et al. (2005). Amplification reactions $(25 \mu \mathrm{l})$ contained $50 \mathrm{ng}$ of DNA, $5 \times$ GoTaq Flexi Buffer, $0.2 \mathrm{mM}$ of each $\mathrm{dNTP}, 1.5 \mathrm{mM} \mathrm{MgCl}_{2}, 4$ pmol of each primer pair, and $1 \mathrm{U}$ of GoTaq Taq Polymerase (Promega Corp., Madison, WI). Amplification conditions included an initial denaturation at $94^{\circ} \mathrm{C}$ for $3 \mathrm{~min}$; followed by 35 cycles of denaturation for $30 \mathrm{~s}$ at $94^{\circ} \mathrm{C}$, annealing for $30 \mathrm{~s}$ at $54.2^{\circ} \mathrm{C}$, and extension for $1 \mathrm{~min}$ at $72^{\circ} \mathrm{C}$; and a final extension for $10 \mathrm{~min}$ at $72^{\circ} \mathrm{C}$. Excess primers and salts were removed from the amplification products using the Ultra Clean PCR Clean-Up Kit (MoBio Laboratories, Inc., Carlsbad, CA). Sequencing was carried

TABLE 1. Native Washington yeast strains and Botrytis isolates used in this study

\begin{tabular}{|c|c|c|c|c|c|}
\hline \multirow[b]{2}{*}{ Species } & \multirow[b]{2}{*}{ Isolate } & \multicolumn{3}{|c|}{ GenBank accession numbers ${ }^{\mathrm{x}}$} & \multirow[b]{2}{*}{ Cultivar $^{\mathrm{y}}$} \\
\hline & & ITS/D1-D2 & G3PDH & HSP60 & \\
\hline Aureobasidium pullulans & P01A006 & JX188090 & $\ldots$ & $\ldots$ & Riesling \\
\hline Candida saitoana & $\mathrm{P} 45 \mathrm{~A} 002$ & JX188109 & $\ldots$ & $\ldots$ & Chardonnay \\
\hline Curvibasidium pallidicorallinum & P45C001 & JX188148 & $\ldots$ & $\ldots$ & Chardonnay \\
\hline Metschnikowia chrysoperlae & P34A004 & JX188171 & $\ldots$ & $\ldots$ & Chardonnay \\
\hline M. chrysoperlae & P34B007 & JX188169 & $\ldots$ & $\ldots$ & Chardonnay \\
\hline M. chrysoperlae & P40A002 & JX188173 & $\ldots$ & $\ldots$ & Riesling \\
\hline M. pulcherrima & P01A016 & JX188181 & $\ldots$ & $\ldots$ & Riesling \\
\hline M. pulcherrima & P01C004 & JX188183 & $\ldots$ & $\ldots$ & Riesling \\
\hline Meyerozyma guilliermondii & P34D003 & JX188191 & $\ldots$ & $\ldots$ & Riesling \\
\hline Saccharomyces cerevisiae & HNN11516 & KX891350 & $\ldots$ & $\ldots$ & Cabernet Sauvignon \\
\hline Wickerhamomyces anomalus & P42B001 & JX188245 & $\ldots$ & $\ldots$ & Riesling \\
\hline Botrytis cinerea & 101V3Dd & KU173126 & KY930930 & KY930931 & Chardonnay \\
\hline B. cinerea & $111 \mathrm{bb}$ & KU173125 & KY930932 & KY930933 & Riesling \\
\hline B. cinerea & $207 \mathrm{a}$ & KU173124 & KY930934 & KY930935 & Riesling \\
\hline B. cinerea & $207 \mathrm{cb}$ & KU173120 & KY930936 & KY930937 & Riesling \\
\hline B. cinerea & $207 \mathrm{db}$ & KU173128 & KY930938 & KY930939 & Riesling \\
\hline B. cinerea & $207 \mathrm{e}$ & KU173121 & KY930940 & KY930941 & Riesling \\
\hline B. cinerea & $407 \mathrm{cb}$ & KU173122 & KY930942 & KY930943 & Riesling \\
\hline B. cinerea & $407 \mathrm{da}$ & KU173123 & KY930944 & KY930945 & Riesling \\
\hline Botrytis sp. ${ }^{\mathrm{z}}$ & R1V55\#13 & KU173127 & KY930946 & KY930947 & Chardonnay \\
\hline
\end{tabular}

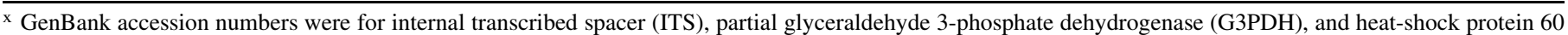
(HSP60) sequences, except for the D1-D2 region of the 26S ribosomal RNA of Saccharomyces cerevisiae (Bourret et al. 2013; Dugan et al. 2002).

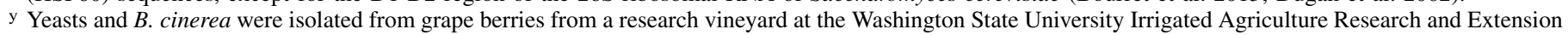
Center in Prosser, WA. The $S$. cerevisiae was isolated from a native fermentation of grape from Paterson, WA.

z Showed strong identity to B. prunorum by multilocus sequence analysis (Fig. 2). 
out using the BigDye Terminator Cycle Sequencing Kit (v. 3.1; Applied Biosystems, Foster City, CA) at ELIM (Biopharmaceuticals, Inc., Hayward, CA). Sequence data were assembled and analyzed using Molecular Evolutionary Genetics Analysis (MEGA) software 7 (Kumar et al. 2016). Provisional taxonomic assignments were made from matches to GenBank accessions using Blasntn (Altschul et al. 1997). Nucleotide sequences were deposited in GenBank under accession numbers KU173120 through KU173128 for ITS; KY930930, 932, 934, 936, 938, 940, 942, 944, and 946 for G3PDH; and KY930931, 933, 935, 937, 939, 941, 942, 945, and 947 for HSP60 (Table 1).

Virulence of $\boldsymbol{B}$. cinerea isolates on grape berries. $B$. cinerea isolates were cultured on $1 / 2 \mathrm{~V} 8$ agar at $25^{\circ} \mathrm{C}$ under a 12 -h photoperiod for 4 days. Spores were collected, washed in sterile water, concentrated using centrifugation at $18,000 \times g$ for $3 \mathrm{~min}$, and resuspended in water. The concentration of the spores was determined using a hemocytometer and adjusted to give a concentration of $10^{4}$ spores $\mathrm{ml}^{-1}$. Each inoculation consisted of $1 \mu \mathrm{l}$ (10 spores) of a spore suspension introduced into a wound site. Ten berries were inoculated for each Botrytis isolate. Inoculated berries were incubated at $25^{\circ} \mathrm{C}$ for 10 days, and disease symptoms were evaluated daily according to the following visual rating scale (0 to 7): $0=$ healthy berry with no or minor browning around wound site; 1 = brown spots on the berry surface; 2 =browning over $<50 \%$ of the berry surface; 3 = browning over $>50 \%$ of the berry surface; $4=$ browning over the entire berry surface; $5=$ Botrytis spores covering the entire berry; $6=$ as in 5 , plus thinning and wrinkling of the berry skin; and $7=$ as in 6 , plus berry skin with visible shrinkage (Fig. 1C). The area under the disease progress curve (AUDPC) was calculated for disease severity ratings taken at 3 to 10 days postinoculation (dpi) according to the equation of Campbell and Madden (1990). The experiment was conducted three times.

Sensitivity of native yeasts to fungicides. Ten native yeast strains were tested for their sensitivity to the fungicides Luna Privilege (fluopyram; Bayer [Pty] Ltd., Port Elizabeth, South Africa), Pristine (pyraclostrobin and boscalid; BASF Corporation, Holly Springs, NC), Procure (triflumizole; Chemtura, Middlebury, CT), and Vivando (metrafenone; BASF Corporation) using a modified National Committee for Clinical Laboratory Standards (1984) procedure.

\section{A Top view Cross-section}

1
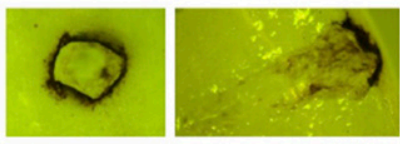

2
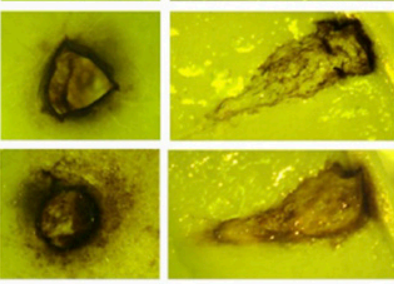

4

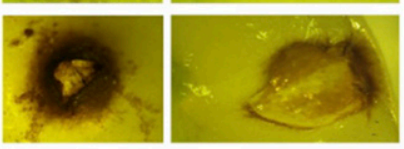

B

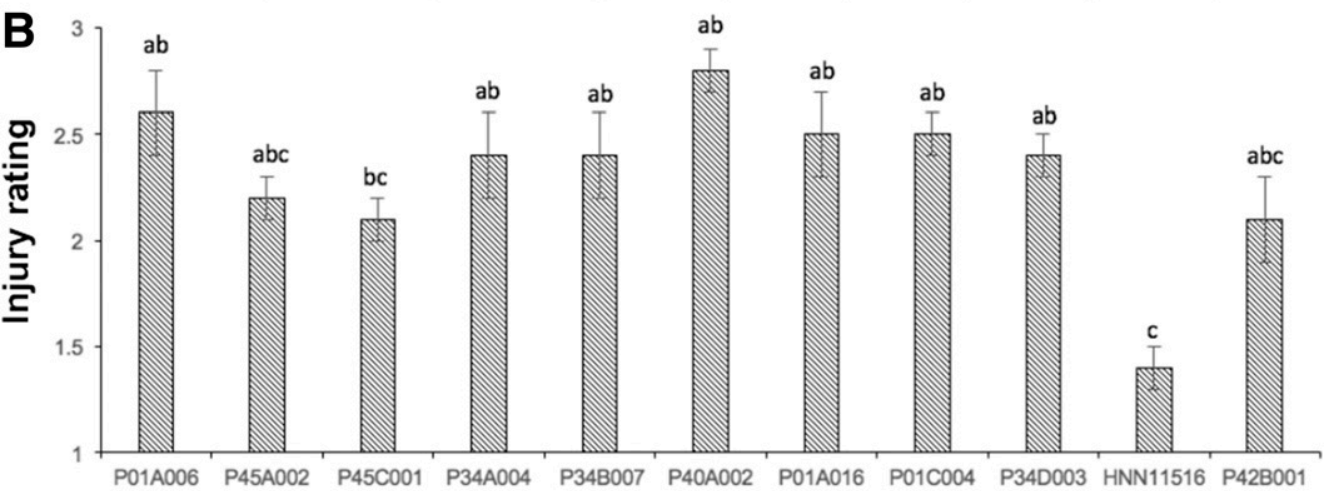

Yeast strain

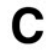

C $0 \quad 1$

2 3

4

5

6

7

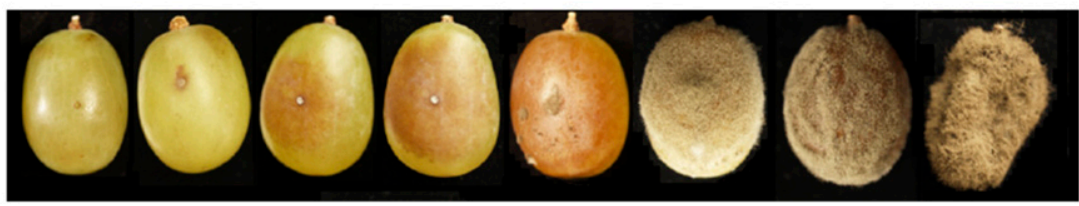

Fig. 1. A, Yeast-induced injury rating on a scale of 1 to 4 , where $1=$ light brown discoloration along the wound circumference edge or within the wound site, $2=$ brown or black spots around the exterior surface of or within the wound site, $3=$ brown or black necrosis around the perimeter of and within the wound site, and $4=$ intense dark brown or black necrosis around the entire perimeter of and within the wound site. B, Extent of discoloration associated with yeast colonization of Thompson Seedless berries at 10 days postinoculation. Two hundred yeast cells were applied to wounds, and discoloration in and around the wound site was rated on a scale of 1 to 4, as in A. C, Botrytis disease severity rating on a scale of 0 (healthy) to 7 (grape skin thin and wrinkled; berry shrunken to one-half the size of healthy), based on Archbold et al. (1997). 
These fungicides are used commonly in Washington vineyards to control Botrytis bunch rot. Yeast cells were cultured for $48 \mathrm{~h}$ on glucose yeast peptone agar (GYP agar; $0.5 \%$ glucose, $0.3 \%$ yeast extract, $0.5 \%$ peptone, and $1.5 \%$ agar), washed once, and suspended in $1 \mathrm{ml}$ of sterile water. Population densities were adjusted to $10^{6}$ cells $\mathrm{ml}^{-1}$ using a hemocytometer. Then, $100 \mu \mathrm{l}\left(10^{5}\right.$ cells $)$ was spread on a GYP agar plate. Each fungicide was diluted to 50,500, and 1,000 $\mu \mathrm{g}$ $\mathrm{ml}^{-1}$ by weight of formulation. Fungicide dilutions $(20 \mu \mathrm{l})$ were applied to 1-mm-diameter autoclaved disks of Whatman number 1 filter paper. Three fungicide-treated filter disks were laid over the yeast and assay plates were incubated for $72 \mathrm{~h}$ at $20^{\circ} \mathrm{C}$ under a $12-\mathrm{h}$ photoperiod. Results were recorded as ++ when yeast colony growth was completely inhibited immediately adjacent to the filter paper disk, + when colonies were reduced in size relative to the nonfungicide control, and - when no yeast growth inhibition occurred around the filter paper disk.

Colonization of grape berries by native yeasts and identification of yeasts recovered from colonized berry tissue. Individual intact berries with pedicels were cut from clusters of Thompson Seedless grape. Berries were washed three times in water, treated once in $70 \%$ ethanol for $1 \mathrm{~min}$ and once in $0.5 \%$ sodium hypochlorite $(\mathrm{NaClO})$ for $5 \mathrm{~min}$, and rinsed twice with autoclaved distilled water. Berries were dried under a laminar flow hood for $1 \mathrm{~h}$, and transferred to autoclaved, lidded plastic boxes ( 11.7 by 9 by $10 \mathrm{~cm}$ ). Each box contained 12 berries that were separated by strips of clean, plastic-backed bench liner.

Yeast strains were cultured on yeast extract peptone dextrose (1\% Bacto yeast extract, $2 \%$ Bacto peptone, and 2\% dextrose) and incubated for $48 \mathrm{~h}$ at $25^{\circ} \mathrm{C}$ under a 12 -h photoperiod. Cell suspensions were adjusted to $10^{5}$ cells $\mathrm{ml}^{-1}$ using a hemocytometer. A single 3-mm-deep wound was made on each intact berry using a sterile wooden toothpick. Cell suspensions $(2 \mu \mathrm{l} \mathrm{each})$ at $10^{5}, 10^{6}$, or $10^{7}$ cells $\mathrm{ml}^{-1}(200,2,000$, or 20,000 cells/wound) were pipetted into wounds. Sterile water served as the inoculum for the control treatment. Berries were incubated at $25^{\circ} \mathrm{C}$ for $2,4,6$, and 10 days. After 10 days, each berry was bisected through the wound center to evaluate yeast-associated injury on the basis of a scale of 1 to 4 , where $1=$ light brown discoloration along the wound circumference edge or within the wound site, 2 = brown or black spots around the exterior surface of or within the wound site, 3 = brown or black necrosis around the perimeter of and within the wound site, and $4=$ intense dark brown or black necrosis around the entire perimeter of and within the wound site. Tissue from the wound site was excised from each berry using a sterile scalpel and macerated in $1 \mathrm{ml}$ of sterile water in the presence of $0.64-\mathrm{cm}$ ceramic sphere beads (MP Biomedicals) for $1 \mathrm{~min}$ on a vortex homogenizer. Yeast population densities were determined using a hemocytometer. For each treatment (yeast) and time point, 10 berries were inoculated and each berry served as a replicate. Colonization experiments were conducted three times and injury evaluations were conducted twice.

To determine whether the yeasts quantified from inoculated berries at day 10 were the same as those in the initial inoculum, $100 \mu \mathrm{l}$ of yeast cells was diluted $10^{3}$-fold and spread on WLNA (Hardy Diagnostics, Santa Maria, CA) supplemented with streptomycin at $50 \mu \mathrm{g} \mathrm{ml}^{-1}$. Plates were incubated at $25^{\circ} \mathrm{C}$ for 3 days. Six representative colonies were selected from each yeast plating; when observed, colonies having visible morphological differences also were selected. ITS sequences were obtained and compared with accessions in GenBank (Altschul et al. 1997).

In vitro inhibition of Botrytis isolates by native yeasts. Yeast strains were grown on GYP agar for $48 \mathrm{~h}$. Cells were washed once in sterile water and adjusted to $1 \times 10^{9}$ cells ml-1 using a hemocytometer. In an initial screen, 50 strains representing 16 genera were selected from a collection of 250 strains (Bourret et al. 2013 ) and assayed for activity against $B$. cinerea isolate 101V3Dd. A yeast cell suspension $(100 \mu \mathrm{l})$ was introduced at the center of a GYP agar plate. A 5-mm plug from the leading edge of a 2-day-old culture of $B$. cinerea 101 V3Dd was placed at the center of each Petri plate. Plates were incubated at $20^{\circ} \mathrm{C}$ under a 12 -h photoperiod, and the diameter of the fungal colony was measured when the leading edge of the fungal colony on control plates reached the perimeter of the agar, usually at 5 days. Sterile water was used as the control. Yeast strains were considered to have inhibitory activity if the colony diameter of $B$. cinerea was $<5 \mathrm{~mm}$. Each treatment (yeast) was replicated three times, with a single plate serving as a replicate. The experiment was repeated three times.

In a quantitative assay of in vitro inhibition of $B$. cinerea isolates $101 \mathrm{~V} 3 \mathrm{Dd}, 111 \mathrm{bb}, 207 \mathrm{cb}, 207 \mathrm{e}$, and $407 \mathrm{cb}$, two $2-\mu \mathrm{l}$ aliquots of yeast cell suspensions were placed $1 \mathrm{~cm}$ from the edge of the GYP agar at opposing spots on the plate and incubated at $24^{\circ} \mathrm{C}$ under a 12 -h photoperiod. After $48 \mathrm{~h}$, a 5 -mm plug of a 2-day-old culture of $B$. cinerea was placed in the center of each plate. Control plates were inoculated with medium without yeast. When the fungus reached the perimeter of the plate (approximately 4 days), measurements were taken of the distance between the yeast and fungal colonies at the yeast-fungus interface, and the radius of the fungal colony where yeast was not present. The inhibition index was defined as $[y /(x+y)] \times 100$, where $y$ is the distance between the leading edge of the fungus and the center of the yeast colony and $x$ is distance between the leading edge of the fungus and the center of the agar plug (Mavrodi et al. 2012). Each treatment of a yeast and Botrytis isolate combination was replicated three times, with a single plate serving as a replicate. The experiment was conducted three times.

Biocontrol activity of native yeasts in vivo. For each yeast strain, 10 Thompson Seedless berries were wounded and inoculated with 200 yeast cells, as described above. Berries were incubated at $25^{\circ} \mathrm{C}$ for $48 \mathrm{~h}$. Approximately 10 spores of each $B$. cinerea isolate were introduced to the wound site and the berries were incubated at $25^{\circ} \mathrm{C}$ for an additional 8 days. Disease symptoms were evaluated using the 0 -to-7 visual rating scale (Fig. 1C). Each berry served as a replicate and the experiment was conducted three times.

Growth of native yeasts and Botrytis isolates on Biolog microplates. Eleven yeast strains and five $B$. cinerea isolates were grown on YT MicroPlates (Biolog Inc., Hayward, CA). Yeast cells were grown at $25^{\circ} \mathrm{C}$ for $48 \mathrm{~h}$ on BUY agar (Biolog Inc.). Suspensions in sterile water were adjusted to an absorbance at $630 \mathrm{~nm}\left(\mathrm{~A}_{630}\right)$ reading of 0.05 and $100 \mu \mathrm{l}$ was added to each well of the YT microplate. Botrytis strains were cultured on BUY agar at $25^{\circ} \mathrm{C}$ for 48 to $96 \mathrm{~h}$ until spores were observed. Washed spores $(100 \mu \mathrm{l})$ adjusted to $10^{4}$ spores $\mathrm{ml}^{-1}$ in $0.2 \%$ water agar water were used for microplate inoculation. Microplates were incubated at $26^{\circ} \mathrm{C}$. Readings at $\mathrm{A}_{590}$ $\mathrm{nm}$ were taken at 0 and 4 days using a BioTek ELx 808 spectrophotometer (BioTek Instruments, Inc., Winooski, VT). To normalize absorbance values of each microplate, the reading from oxidation control well A1 was subtracted from wells A2 to C12, and that of assimilation control well D1 was subtracted from wells D2 to H12. For net $\mathrm{A}_{630}$ values, day 0 readings for each well were subtracted from those of day 4 . Net $\mathrm{A}_{630}$ values $>0.10$ were considered to be positive for growth. The experiment was repeated once.

Statistical analysis. Berries in colonization and biocontrol experiments were arranged by treatments in a partially balanced incomplete block design; other experiments were done in a completely randomized design. Differences in mean AUDPC, AUGC, yeast injury ratings, and Botrytis disease severity ratings were determined among treatments using a Kruskal-Wallis oneway analysis of variance (ANOVA) test followed by Dunn's test for multiple comparisons $(P=0.05)$, (Statistix 8.1; Analytical Software, St. Paul, MN). Botrytis in vitro and in vivo inhibition data and yeast population density comparisons were performed using the two-way ANOVA. Means were separated into letter classes using Tukey or Fisher's least significant difference pairwise comparisons $(P<0.05)$. Bartlett's test for homogeneity of variances was used to determine whether data from separate experiments could be combined $(P<0.05)$. The results from the YT microplates for each strain were subjected to two-way ANOVA with Minitab 17, 
cluster analysis, and logistics regression (SAS Institute, Inc., Cary, NC).

\section{RESULTS}

Characterization of the Botrytis isolates. Traditional morphological classification of the Botrytis isolates was previously determined by Dugan and Lupien (Dugan et al. 2002). Eight of the nine isolates shared identical ITS sequences; however, isolate R1V55\#13 harbored a single A polymorphism (Fig. 2). Partial sequences of G3PDH and HSP60 indicated that two main clades were distinguished in the genus Botrytis. Isolates $111 \mathrm{bb}, 101 \mathrm{~V} 3 \mathrm{Dd}$, 2017a, 207cb, 207db, 207e, 407cb, and 407da clustered together, and their gene sequences were identical for G3PDH and HSP60. Isolate R1V55\#13 varied at a few sites that distinguished it from other groups and it was closely related to B. prunorum (Fig. 2). The colony morphology of isolate R1V55\#13 also differed from the other the Botrytis isolates on KMB, APDA, and PAM, and it was similar to the colonies of B. prunorum on the three media described by Ferrada et al. (2016) (Supplementary Fig. S1).

Virulence of $B$. cinerea isolates on grape berries. Because the Botrytis isolates had been in storage for several years, we completed Koch's postulates with them and showed that all nine isolates were pathogenic on grape berries. Eight of the nine Botrytis isolates caused substantial rot on Thompson Seedless berries over a 10-day interval. Relative virulence of the isolates was quantified by comparing the AUDPC for each pathogen isolate and disease severity at 10 days after inoculation (Table 2). Based on AUDPC, isolates 207a was significantly $(P<0.05)$ more virulent than isolates $111 \mathrm{~b}, 207 \mathrm{db}$, and R1V55\#13. Although the pathogen isolates were not identical in virulence, generally they caused substantial disease in our tests and most caused severe damage by $6 \mathrm{dpi}$. The exception was isolate R1V55\#13, which was significantly $(P<0.05)$ less virulent than the other eight strains based on disease ratings and AUDPC (Table 2). Isolate R1V55\#13 was also the slowest growing of the Botrytis isolates (Table 2). The greatly reduced virulence of R1V55\#13 is supported by the finding that it does not cluster with other B. cinerea and is more closely related to B. prunorum.

Sensitivity of yeasts strains to commercial fungicides. The native yeasts used in this study differed in their responses to three of four commercial fungicide formulations commonly used to control Botrytis bunch rot in Washington vineyards (Table 3). After $72 \mathrm{~h}$, all yeast strains grew on Vivando to a similar degree; they were not different than the no-fungicide controls, and were considered to be tolerant to Vivando. In addition, Curvibasidium pallidicorallinum $\mathrm{P} 45 \mathrm{C} 001$ was not affected by the other three fungicides. However, reduction in colony size was observed for most yeasts with Pristine or Luna Privilege. Growth of Metschnikowia chrysoperlae, M. pulcherrima, and A. pullulans was completely inhibited by Procure at $500 \mu \mathrm{g} \mathrm{ml}^{-1}$.

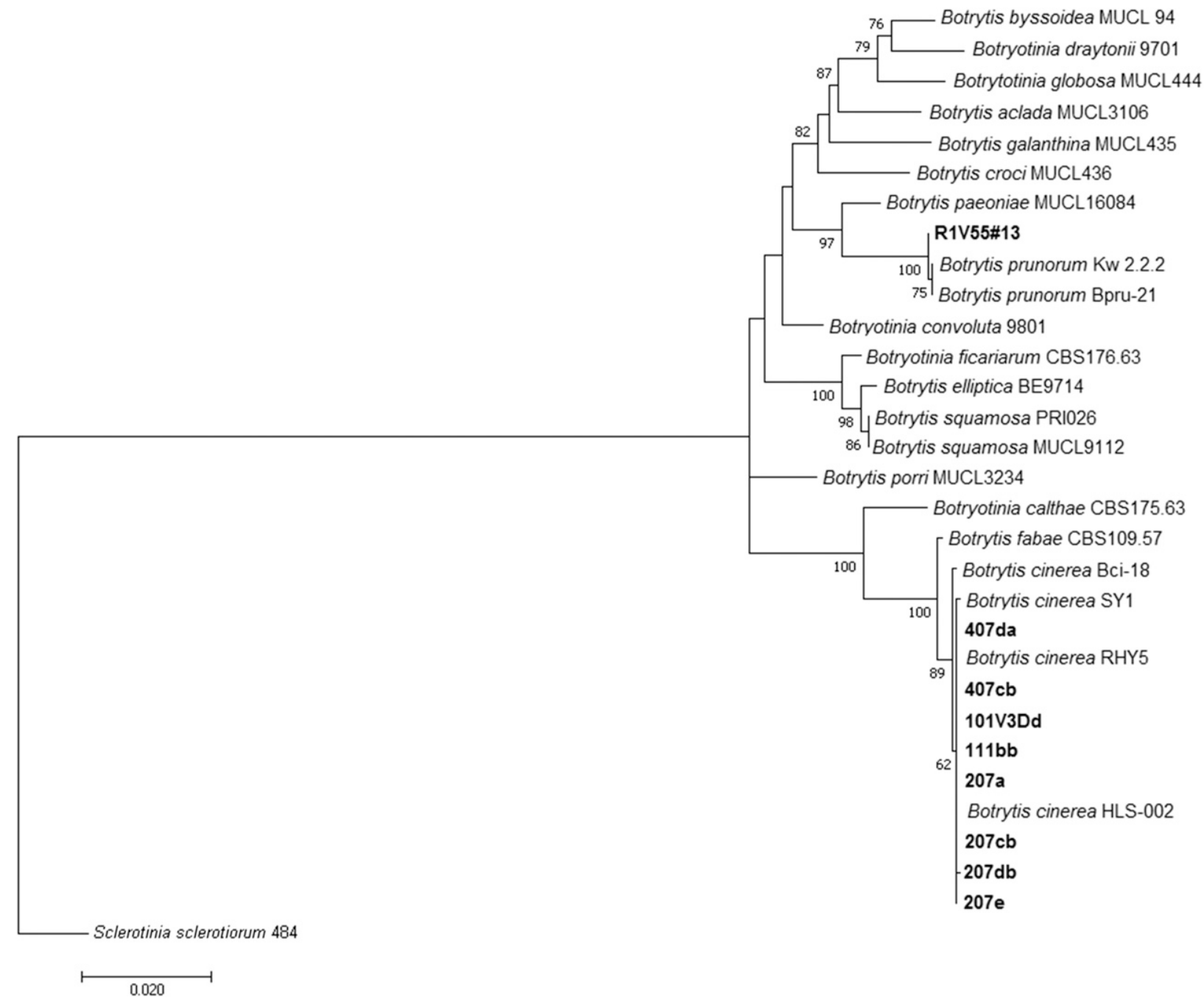

Fig. 2. Molecular phylogenetic analysis of Botrytis taxa and an outgroup species based on combined glyceraldehyde-3-phosphate dehydrogenase and heat-shock protein 60 data by maximum-likelihood method. The evolutionary history was inferred by using the maximum-likelihood method based on the Kimura twoparameter model (Kimura 1980). The tree is drawn to scale, with branch lengths measured in the number of substitutions per site. Bootstrap values greater than $60 \%$ are shown at the nodes. Evolutionary analyses were conducted in MEGA7 (Kumar et al. 2016). 
Grape berry colonization and injury by yeast strains. Populations sizes of the native yeasts and yeast-like fungus A. pullulans on grape berries increased 10,000 -fold by 2 days after inoculation, increasing from 200 cells to approximately 1 million per wound, and then reached approximately 10 million cells per wound at 10 days (Table 4 ). The population density of Wickerhamomyces anomalus $\mathrm{P} 42 \mathrm{~B} 001$ at day 2 was significantly $(P<$ $0.05)$ greater than all of the other strains, except for Meyerozyma guilliermondii P34D003 and S. cerevisiae HNN11516. The native yeasts caused mild browning of the berry wound site perimeter and internal wound tissue (ratings of 1.0 to 2.75 ) at $10 \mathrm{dpi}$, albeit when

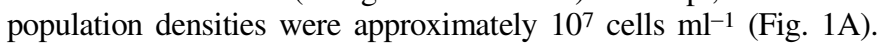
Observations of multiple berries indicated that $A$. pullulans caused the most consistent and pronounced browning (ratings of 1.6 to 2.5), even though the mean values of injury ratings for the strains did not differ significantly, except for $S$. cerevisiae HNN11516 (Fig. 1B). Among replicate berries inoculated with a given strain, there was variability in browning. S. cerevisiae caused the least amount of browning, and was most similar to the no-yeast control. The reisolated colonies of A. pullulans, Candida saitoana, Metschnikowia chrysoperlae $\mathrm{P} 34 \mathrm{~A} 004$, and $W$. anomalus were identical to those originally used. Mixed sequences were detected in M. chrysoperlae P34B007 and

TABLE 2. Virulence of nine Botrytis isolates on wounded Thompson Seedless grape berries

\begin{tabular}{lccc}
\hline Isolate & Disease rating $^{\mathrm{x}}$ & AUDPC $^{\mathrm{y}}$ & AUGC $^{\mathrm{z}}$ \\
\hline $101 \mathrm{~V} 3 \mathrm{Dd}$ & $5.4 \pm 0.1 \mathrm{a}$ & $25.2 \pm 0.9 \mathrm{abc}$ & $8.0 \mathrm{a}$ \\
$111 \mathrm{bb}$ & $5.2 \pm 0.2 \mathrm{a}$ & $22.4 \pm 0.9 \mathrm{c}$ & $7.9 \mathrm{a}$ \\
$207 \mathrm{a}$ & $5.6 \pm 0.2 \mathrm{a}$ & $27.9 \pm 0.8 \mathrm{a}$ & $7.7 \mathrm{ab}$ \\
$207 \mathrm{cb}$ & $5.7 \pm 0.1 \mathrm{a}$ & $26.7 \pm 0.8 \mathrm{ab}$ & $7.7 \mathrm{ab}$ \\
$207 \mathrm{db}$ & $5.4 \pm 0.2 \mathrm{a}$ & $23.9 \pm 0.9 \mathrm{bc}$ & $7.7 \mathrm{ab}$ \\
$207 \mathrm{e}$ & $5.4 \pm 0.2 \mathrm{a}$ & $26.2 \pm 0.8 \mathrm{ab}$ & $7.9 \mathrm{a}$ \\
$407 \mathrm{cb}$ & $5.5 \pm 0.2 \mathrm{a}$ & $26.9 \pm 0.9 \mathrm{ab}$ & $7.7 \mathrm{ab}$ \\
$407 \mathrm{da}$ & $5.1 \pm 0.2 \mathrm{a}$ & $26.7 \pm 0.7 \mathrm{ab}$ & $8.0 \mathrm{a}$ \\
R1V55\#13 & $2.1 \pm 0.1 \mathrm{~b}$ & $12.3 \pm 0.5 \mathrm{~d}$ & $7.4 \mathrm{~b}$ \\
\hline
\end{tabular}

${ }^{x}$ Disease severity was rated after 8 days on a scale of 0 (healthy) to 7 (grape skin thin and wrinkled; berry shrunken to one-half the size of healthy). Values are the average of 9 to 10 berries in three independent experiments (total $n=27$ to 30 ), determined using Kruskal-Wallis analysis of variance followed by Dunn's test for multiple comparisons. Data from the experiments were pooled. Letters indicate significant $(P<0.05)$ differences among means within each column.

y Area under the disease progress curve (AUDPC) was calculated from a plot of disease severity ratings from day 3 to day 10 . Values were calculated from average disease ratings of 9 to 10 berries from three experiments $(n=27$ to $30)$. Data from the experiments were pooled.

${ }^{z}$ Area under the growth curve (AUGC) on half-strength V8 agar was calculated over 4 days. Values represent the means of four replicates in each of two experiments $(n=8)$. Data from the experiments were pooled.
P40A002, M. pulcherrima, Meyerozyma guilliermondii, Curvibasidium pallidicorallinum, and $S$. cerevisiae.

Inhibition activity of the native yeasts in vitro. Eleven yeast strains showing consistent inhibition of $B$. cinerea in the in vitro qualitative assays (Kramer 2015) were selected from the yeast collection for further testing. In a preliminary in vitro inhibition experiment, we found that certain yeast strains were inhibitory only to certain $B$. cinerea isolates. These yeast-Botrytis pairs also showed inhibitory interactions in inhibition index studies (Table 5). A. pullulans P01A006 inhibited all five Botrytis isolates used in the inhibition index experiments. C. pallidicorallinum $\mathrm{P} 45 \mathrm{C} 001$ inhibited three of the five isolates; Metschnikowia pulcherrima P01A016 and P01C004, Meyerozyma guilliermondii P34D003, S. cerevisiae HNN11516, and $W$. anomalus $\mathrm{P} 42 \mathrm{~B} 001$ inhibited two isolates. The other strains inhibited only one Botrytis isolate. B. cinerea isolate $207 \mathrm{cb}$ was the most sensitive to the native yeasts, whereas isolates $407 \mathrm{cb}$ and 101V3Dd were the least sensitive. The results demonstrated that yeast strains of the same species varied in their control of $B$. cinerea, and that the pathogen isolates differentially responded to each yeast in the in vitro assays.

Biocontrol activity of native yeasts on grape berries. All yeast strains significantly suppressed at least one of the four Botrytis isolates on the grape berries. However, the Botrytis isolates were differentially sensitive to the yeasts (Table 6). In general, the most effective strains were A. pullulans P01A006, Metschnikowia chrysoperlae P34A004 and P40A002, M. pulcherrima P01A016 and $\mathrm{P} 01 \mathrm{C} 004$, Meyerozyma guilliermondii $\mathrm{P} 34 \mathrm{D} 003$, and $S$. cerevisiae HNN11516. The disease suppressive capacities of Candida saitoana P45A002, Curvibasidium pallidicorallinum P45C001, Metschnikowia chrysoperlae $\mathrm{P} 34 \mathrm{~B} 007$, and $W$. anomalus $\mathrm{P} 42 \mathrm{~B} 001$ varied among the different Botrytis isolates relative to the no-yeast control.

A. pullulans P01A006 was the only strain that inhibited all of the Botrytis isolates both in vitro and on grape berries. With Botrytis isolates $111 \mathrm{bb}$ and $207 \mathrm{cb}$, there was a general trend for yeasts that were inhibitory in vitro to be suppressive on the berries. In contrast, with Botrytis isolate $407 \mathrm{cb}$, there was a trend for noninhibitory yeasts to be suppressive on the berries.

Growth of yeasts and $B$. cinerea on Biolog microplates. Metabolite oxidation (wells A2 to C12) and assimilate utilization (wells D2 to H12) by yeast and B. cinerea strains were profiled using Biolog YT microplates. The percent utilization of the 35 oxidation and 59 assimilation compounds by each yeast and Botrytis isolate was reproducible in two separate experiments. Visual inspection indicated that the compounds utilized in both experiments comprised seven distinct utilization groups among the yeast strains and Botrytis isolates (Table 7; Supplementary Fig. S2). Visual analysis was supported by principal component analysis (PCA) (Supplementary Fig. S3) and cluster analysis (data not shown). Group 1 comprised

TABLE 3. In vitro sensitivity of native yeast strains to four commonly used vineyard fungicides ${ }^{\mathrm{y}}$

\begin{tabular}{|c|c|c|c|c|c|c|c|c|c|c|c|c|}
\hline \multirow[b]{2}{*}{ Yeast species, strain ${ }^{z}$} & \multicolumn{3}{|c|}{ Luna Privilege } & \multicolumn{3}{|c|}{ Pristine } & \multicolumn{3}{|c|}{ Procure } & \multicolumn{3}{|c|}{ Vivando } \\
\hline & 50 & 500 & 1,000 & 50 & 500 & 1,000 & 50 & 500 & 1,000 & 50 & 500 & 1,000 \\
\hline Ap P01A006 & - & + & + & + & + & + & + & ++ & ++ & - & - & - \\
\hline Cs P45A002 & - & + & + & - & - & + & - & - & - & - & - & - \\
\hline Cp P45C001 & - & - & - & - & - & - & - & - & - & - & - & - \\
\hline Mc P34A004 & - & + & + & + & + & + & + & ++ & ++ & - & - & - \\
\hline Mc P34B007 & - & + & + & - & + & + & + & ++ & ++ & - & - & - \\
\hline Mc P40A002 & - & + & + & + & + & + & + & ++ & ++ & - & - & - \\
\hline Mp P01A016 & - & + & + & + & + & + & + & ++ & ++ & - & - & - \\
\hline Mp P01C004 & - & + & + & + & + & + & + & ++ & ++ & - & - & - \\
\hline Mg P34D003 & - & - & - & + & + & + & - & - & - & - & - & - \\
\hline Wa P42B001 & - & - & + & + & + & + & - & + & + & - & - & - \\
\hline
\end{tabular}

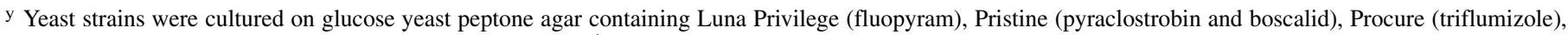
and Vivando (metrafenone) at 50, 500, and 1,000 $\mu \mathrm{g} \mathrm{m} \mathrm{m}^{-1}$ for $72 \mathrm{~h}$ at $20^{\circ} \mathrm{C}$ under a 12 -h photoperiod. Experiments were repeated three times. Symbols: indicates no inhibition of colony size relative to the no-fungicide control, + indicates visible inhibition of colony size relative to control, and ++ indicates complete inhibition of colony growth.

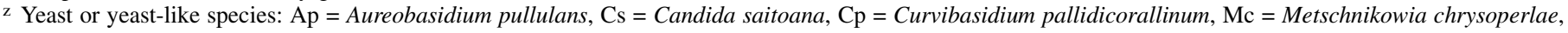
$\mathrm{Mp}=$ M. pulcherrima, $\mathrm{Mg}=$ Meyerozyma guilliermondii, Sc: Saccharomyces cerevisiae, and Wa = Wickerhamomyces anomalus . 
three yeast strains that utilized 70.2 to $81.9 \%$ of the total Biolog metabolites. Groups 3, 4, and 5 included yeasts that were moderate utilizers, at 40.4 to $63.8 \%$ utilization. Groups 2, 5, and 6 comprised singletons of A. pullulans, W. anomalus (moderate utilizers), and C. pallidicorallinum (poor utilizer), respectively. The Botrytis isolates, also poor utilizers at 22.3 to $31.9 \%$ utilization, were placed in group 7.

Yeasts from all six utilization groups reduced the severity of disease caused by the Botrytis isolates. This was not unexpected because, as a group, the Botrytis isolates utilized 20 of the 59 assimilates $(33.9 \%)$, whereas the yeasts in group 6 used 25 assimilates $(42.3 \%)$, of which $9(6.6 \%)$ were coutilized between the two groups. In contrast, the yeasts in group 1 used 42 assimilates (71.2\%), of which $16(27.1 \%)$ were also utilized by the Botrytis group. Twelve compounds produced by grape berries (Conde et al.

TABLE 4. Log population densities of yeast cells in artificial wounds on Thompson Seedless grape over a 10-day interval ${ }^{\mathrm{y}}$

\begin{tabular}{lllll}
\hline Yeast species, strain & Day 2 & Day 4 & Day 6 & Day 10 \\
\hline Ap P01A006 & $6.0 \mathrm{e}$ & $6.5 \mathrm{~b}$ & $6.8 \mathrm{cdef}$ & $7.1 \mathrm{abcd}$ \\
Cs P45A002 & $6.3 \mathrm{bcd}$ & $6.7 \mathrm{~b}$ & $6.8 \mathrm{bcdef}$ & $7.0 \mathrm{bcd}$ \\
Cp P45C001 & $6.1 \mathrm{de}$ & $6.4 \mathrm{~b}$ & $6.6 \mathrm{f}$ & $6.8 \mathrm{~d}$ \\
Mc P34A004 & $6.1 \mathrm{cde}$ & $6.6 \mathrm{~b}$ & $6.9 \mathrm{ef}$ & $7.2 \mathrm{abcd}$ \\
Mc P34B007 & $6.1 \mathrm{cde}$ & $6.4 \mathrm{~b}$ & $6.9 \mathrm{cdef}$ & $7.0 \mathrm{~cd}$ \\
Mc P40A002 & $6.3 \mathrm{bcde}$ & $6.5 \mathrm{~b}$ & $7.1 \mathrm{ab}$ & $7.4 \mathrm{ab}$ \\
Mp P01A016 & $6.2 \mathrm{bcde}$ & $6.6 \mathrm{~b}$ & $7.1 \mathrm{abc}$ & $7.4 \mathrm{abc}$ \\
Mp P01C004 & $6.2 \mathrm{bcde}$ & $6.7 \mathrm{~b}$ & $7.1 \mathrm{abcd}$ & $7.5 \mathrm{a}$ \\
Mg P34D003 & $6.5 \mathrm{ab}$ & $6.9 \mathrm{a}$ & $7.1 \mathrm{abcde}$ & $7.3 \mathrm{ab}$ \\
Sc HNN11516 & $6.3 \mathrm{abc}$ & $6.7 \mathrm{~b}$ & $6.8 \mathrm{def}$ & $7.0 \mathrm{bcd}$ \\
Wa P42B001 & $6.6 \mathrm{a}$ & $7.1 \mathrm{a}$ & $7.3 \mathrm{a}$ & $7.5 \mathrm{ab}$ \\
\hline
\end{tabular}

y Mean log cells per milliliter population densities of three combined experiments. Means in a column with a similar letter are not significantly different according to Tukey's test $(P=0.05)$.

z A suspension $(2 \mu \mathrm{l})$ of $10^{5}$ cells $\mathrm{ml}^{-1}$ (200 cells) was applied to wounded berries, 10 berries per strain per time point. Yeast and yeast-like species: Ap = Aureobasidium pullulans, $\mathrm{Cs}=$ Candida saitoana, $\mathrm{Cp}=$ Curvibasidium pallidicorallinum, $\mathrm{Mc}=$ Metschnikowia chrysoperlae, $\mathrm{Mp}=$ M. pulcherrima, $\mathrm{Mg}=$ Meyerozyma guilliermondii, Sc: Saccharomyces cerevisiae, and $\mathrm{Wa}=$ Wickerhamomyces anomalus.

TABLE 5. In vitro inhibition activity of native yeasts against Botrytis cinerea isolates $101 \mathrm{~V} 3 \mathrm{Dd}, 111 \mathrm{bb}, 207 \mathrm{cb}, 207 \mathrm{e}$, and $407 \mathrm{cb}$ on glucose yeast peptone agar

\begin{tabular}{|c|c|c|c|c|c|}
\hline \multirow[b]{2}{*}{ Yeast species, strain ${ }^{z}$} & \multicolumn{5}{|c|}{ Isolates of Botrytis cinerea ${ }^{\mathrm{y}}$} \\
\hline & 101V3Dd & $111 \mathrm{bb}$ & $207 \mathrm{cb}$ & $207 \mathrm{e}$ & $407 \mathrm{cb}$ \\
\hline Ap P01A006 & 20.6 & $26.4 \mathrm{a}$ & $24.9 \mathrm{a}$ & $25.8 \mathrm{a}$ & $21.5 \mathrm{a}$ \\
\hline Cs P45A002 & na & na & na & $12.9 \mathrm{~b}$ & na \\
\hline Cp P45C001 & na & na & $12.1 \mathrm{~b}$ & $12.1 \mathrm{bc}$ & $11.0 \mathrm{~b}$ \\
\hline Mc P34A004 & na & $14.3 \mathrm{~b}$ & na & na & na \\
\hline Mc P34B007 & na & na & $11.3 \mathrm{bc}$ & na & na \\
\hline Mc P40A002 & na & na & na & $11.3 \mathrm{bc}$ & na \\
\hline Mp P01A016 & na & $11.1 \mathrm{c}$ & na & $10.7 \mathrm{c}$ & na \\
\hline Mp P01C004 & na & $9.5 \mathrm{c}$ & $10.1 \mathrm{c}$ & na & na \\
\hline Mg P34D003 & na & $14.6 \mathrm{~b}$ & $12.5 \mathrm{~b}$ & na & na \\
\hline Sc HNN11516 & na & $7.7 \mathrm{~d}$ & $11.0 \mathrm{bc}$ & na & na \\
\hline Wa P42B001 & na & na & $12.6 \mathrm{~b}$ & $12.3 \mathrm{bc}$ & na \\
\hline
\end{tabular}

y Inhibition index of Botrytis cinerea $=(y / x+y)(100)$, where $y$ is the distance from the center of the yeast colony to the edge of the fungal colony at the yeast-fungus interface, and $x$ is the distance from the center of the fungal colony plug to the leading edge of the fungus. Values represent the averages of three measurements from each of two combined experiments $(n=6)$. Means in the same column with a similar letter are not significantly different $(P<0.05)$ according to the Fisher's protected least significant difference test; na $=$ no inhibitory activity, determined in a preliminary screen (data not shown).

z Yeast and yeast-like species: Ap = Aureobasidium pullulans, $\mathrm{Cs}=$ Candida saitoana, $\mathrm{Cp}=$ Curvibasidium pallidicorallinum, $\mathrm{Mc}=$ Metschnikowia chrysoperlae, $\mathrm{Mp}=M$. pulcherrima, $\mathrm{Mg}=$ Meyerozyma guilliermondii, $\mathrm{Sc}$ : Saccharomyces cerevisiae, and Wa = Wickerhamomyces anomalus.
2007; Fugelsang and Edwards 2007; Gerós et al. 2012; Zhao et al. 2016) were present in the Biolog YT assimilate panel (Table 8). All yeast and Botrytis isolates utilized glucose, which is the most abundant sugar in the berry. However, yeast and Botrytis isolates varied considerably in their ability to utilize common grape carbon sources. For example, $\alpha$-ketoglutaric acid was utilized only by group 1 isolates. D-mannitol was utilized by yeasts but not by Botrytis isolates, and D-xylose in combination with dextrin supported the growth of Botrytis but not of yeasts. Surprisingly, D-xylose by itself was utilized by both yeasts and Botrytis isolates. Sucrose was differentially utilized among both yeasts and Botrytis isolates in our experiments. The Botrytis group (group 7) utilized four of the berry assimilates, whereas yeasts in groups 1 and 6 used eight and four, respectively. The yeast strains and Botrytis isolates coutilized sucrose, D-xylose, or D-raffinose. The data also indicated that yeast groups 1 and 6 had the least degree of overlap in assimilate utilization, both using D-xylose, xylitol, and D-mannitol.

\section{DISCUSSION}

The high genetic variation and plasticity, abundant sporulation, and the polycyclic nature of the $B$. cinerea life cycle continue to render this pathogen problematic for the grape industry (FernándezOrtuño et al. 2012). Grape growers throughout the world are seeking to use fewer chemical pesticides for control of pathogens because of concerns about environmental sustainability, food quality, and fungicide resistance (De Miccolis Angelini et al. 2014; FernándezOrtuño et al. 2015). Isolates of native yeasts are known to exert biological control of fungal diseases such as Botrytis bunch rot (Fleet 2003).

Our collection of Washington $B$. cinerea isolates showed significant differences in the temporal dynamics of disease development on inoculated individual Thompson Seedless grape berries based on AUDPC; however, with the exception of isolate R1V55\#13, all of the isolates tested caused the same level of disease by 10 days after inoculation. Our findings support those of Dugan et al. (2002), who previously compared the virulence of isolates R1V55\#13 and 1101 V3Dd and reported that R1V55\#13 caused lesions on Chardonnay grape berries that were significantly smaller and only one-half

TABLE 6. Suppression of disease caused by Botrytis cinerea on Thompson Seedless grape by native yeast

\begin{tabular}{|c|c|c|c|c|}
\hline \multirow[b]{2}{*}{ Yeast species, strain ${ }^{z}$} & \multicolumn{4}{|c|}{ Isolates of Botrytis cinerea ${ }^{\mathrm{y}}$} \\
\hline & $111 \mathrm{bb}$ & $207 \mathrm{a}$ & $207 \mathrm{cb}$ & $407 \mathrm{cb}$ \\
\hline No-yeast control & $3.8 \mathrm{a}$ & $4.5 \mathrm{a}$ & $5.5 \mathrm{a}$ & $4.0 \mathrm{a}$ \\
\hline Ap P01A006 & $2.1 \mathrm{bc}$ & $2.3 \mathrm{~b}$ & $2.4 \mathrm{bcd}$ & $2.2 \mathrm{bc}$ \\
\hline Cs P45A002 & $3.0 \mathrm{ab}$ & $3.0 \mathrm{ab}$ & $3.3 \mathrm{bc}$ & $2.8 \mathrm{abc}$ \\
\hline Cp P45C001 & $2.8 \mathrm{abc}$ & $2.9 \mathrm{~b}$ & $3.8 \mathrm{ab}$ & $2.8 \mathrm{abc}$ \\
\hline Mc P34A004 & $2.4 \mathrm{bc}$ & $2.4 \mathrm{~b}$ & $2.1 \mathrm{~cd}$ & $2.0 \mathrm{bc}$ \\
\hline Mc P34B007 & $2.6 \mathrm{bc}$ & $2.9 \mathrm{abc}$ & $3.4 \mathrm{abc}$ & $3.1 \mathrm{ab}$ \\
\hline Mc P40A002 & $2.2 \mathrm{bc}$ & $2.1 \mathrm{~b}$ & $1.9 \mathrm{~d}$ & $2.1 \mathrm{bc}$ \\
\hline Mp P01A016 & $2.0 \mathrm{c}$ & $2.1 \mathrm{~b}$ & $2.2 \mathrm{~cd}$ & $1.9 \mathrm{bc}$ \\
\hline Mp P01C004 & $1.9 \mathrm{c}$ & $2.1 \mathrm{~b}$ & $2.0 \mathrm{~d}$ & $1.8 \mathrm{c}$ \\
\hline Mg P34D003 & $2.0 \mathrm{c}$ & $2.0 \mathrm{~b}$ & $3.1 \mathrm{bcd}$ & $2.4 \mathrm{bc}$ \\
\hline Sc HNN11516 & $2.5 \mathrm{bc}$ & $2.5 \mathrm{~b}$ & $2.4 \mathrm{bcd}$ & $2.1 \mathrm{bc}$ \\
\hline Wa P42B001 & $2.7 \mathrm{abc}$ & $2.4 \mathrm{~b}$ & $2.4 \mathrm{bcd}$ & $2.5 \mathrm{bc}$ \\
\hline
\end{tabular}

y Approximately 10 spores of $B$. cinerea isolates $111 \mathrm{bb}, 207 \mathrm{a}, 207 \mathrm{cb}$, or $407 \mathrm{a}$ were applied to a wound $48 \mathrm{~h}$ after inoculation with 200 yeast cells. Disease severity was rated on a scale of 0 (healthy) to 7 (grape covered with sporulating fungus, berry shrunken) 8 days postinoculation. Values are averages of 10 berries from each of two replicated pooled experiments $(n=$ 20). Means in the same column with the same letter are not significantly different $(P<0.05)$.

$\mathrm{z}$ Yeast and yeast-like species: $\mathrm{Ap}=$ Aureobasidium pullulans, $\mathrm{Cs}=$ Candida saitoana, $\mathrm{Cp}=$ Curvibasidium pallidicorallinum, $\mathrm{Mc}=$ Metschnikowia chrysoperlae, $\mathrm{Mp}=M$. pulcherrima, $\mathrm{Mg}=$ Meyerozyma guilliermondii, $\mathrm{Sc}$ : Saccharomyces cerevisiae, and $\mathrm{Wa}=$ Wickerhamomyces anomalus. 
the size of lesions caused by 101V3Dd. Additionally, the significantly slower growth rate of R1V55\#13 as compared with 101V3Dd in vitro prompted the hypothesis that the reduced virulence of R1V55\#13 could be due to a double-stranded RNA virus of $B$. cinerea typically associated with reduced fungal growth and virulence (Castro et al. 2003; Wu et al. 2007). However, phylogenetic analysis revealed that R1V55\#13 does not cluster with other $B$. cinerea isolates and is more closely related to $B$. prunorum, including $B$. prunorum strain Bpru-21 from plum in Chile (Ferrada et al. 2016), which explains the lower virulence of R1V55\#13 on grape. Similarly, Ferrada et al. (2016) reported that $B$. prunorum isolates were less virulent than $B$. cinerea on plum flowers and fruit, apple, and kiwifruit. In addition, the colony morphology of isolate R1V55\#13 on $\mathrm{KMB}$, APDA, and PAM was similar to that of B. prunorum from Chile (Ferrada et al. 2016) and different from the Washington $B$. cinerea isolates. To the best of our knowledge, isolate R1V55\#13 may be the first report of $B$. prunorum from grape and it exemplifies recent differences in host preference, disease phenotype, and morphology among the $B$. cinerea isolates that formed the bases for new species (Dugan 2016; Walker 2016). Overall, this diversity suggests that the Washington population of $B$. cinerea comprises several to many genotypes, and perhaps is part of a Botrytis complex. An expanded survey of Washington Botrytis isolates will be needed to characterize possible members of the complex, and population complexity should be considered when formulating a biocontrol plan.

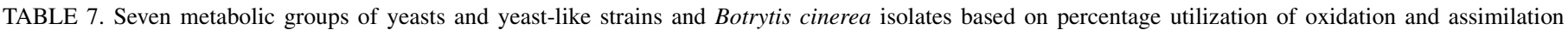
compounds and visual patterns of utilization in Biolog YT microplate assays

\begin{tabular}{|c|c|c|c|c|}
\hline Yeast or Botrytis ${ }^{\mathrm{w}}$ & Group & Oxidation $(\%)^{\mathrm{x}}$ & Assimilation $(\%)^{\mathrm{y}}$ & Total $(\%)^{\mathrm{z}}$ \\
\hline Mg P34D003 & 1 & 85.7 & 79.7 & 81.9 \\
\hline Cs P45A002 & 1 & 71.4 & 81.4 & 77.7 \\
\hline Sc HNN11516 & 1 & 65.7 & 72.9 & 70.2 \\
\hline Ap P01A006 & 2 & 60.0 & 62.7 & 61.7 \\
\hline Mp P01A016 & 3 & 57.1 & 67.8 & 63.8 \\
\hline Mp P01C004 & 3 & 54.3 & 64.4 & 60.6 \\
\hline Мc P40A002 & 3 & 54.3 & 64.4 & 60.6 \\
\hline Мc P34B007 & 4 & 57.1 & 54.2 & 55.3 \\
\hline Mc P34A004 & 4 & 45.7 & 37.3 & 40.4 \\
\hline Wa P42B001 & 5 & 37.1 & 57.6 & 50.0 \\
\hline Cp P45C001 & 6 & 2.9 & 42.4 & 27.7 \\
\hline Bc $101 \mathrm{~V} 3 \mathrm{Dd}$ & 7 & 2.9 & 49.2 & 31.9 \\
\hline $\mathrm{Bc} 407 \mathrm{cb}$ & 7 & 0 & 50.8 & 31.9 \\
\hline Bc $207 \mathrm{a}$ & 7 & 0 & 45.8 & 28.7 \\
\hline Bc $111 \mathrm{bb}$ & 7 & 0 & 44.1 & 27.7 \\
\hline Bc $207 \mathrm{cb}$ & 7 & 0 & 35.6 & 22.3 \\
\hline
\end{tabular}

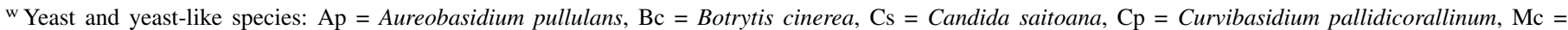

Metschnikowia chrysoperlae, $\mathrm{Mp}=$ M. pulcherrima, $\mathrm{Mg}=$ Meyerozyma guilliermondii, Sc: Saccharomyces cerevisiae, and Wa = Wickerhamomyces anomalus .

$x$ Percentage of the 35 oxidation compounds utilized in both of two independent experiments.

y Percentage of the 59 assimilation compounds utilized in both of two independent experiments.

z Percentage of 94 oxidation plus assimilation compounds utilized in both of two independent experiments.

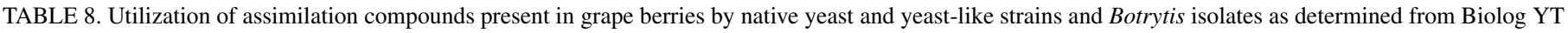
microplate assays

\begin{tabular}{|c|c|c|c|c|c|c|c|c|c|c|c|c|c|}
\hline \multirow[b]{2}{*}{ Strain, isolate ${ }^{z}$} & \multicolumn{13}{|c|}{ Assimilatey } \\
\hline & Dex & D-gl & Glu & Gly & $\mathrm{KG}$ & L-ma & Mal & D-mn & D-rf & Suc & Xyl & D-xy & $\mathrm{D}+\mathrm{D}$ \\
\hline \multicolumn{14}{|l|}{ Yeast group 1} \\
\hline Cs P45A002 & - & + & + & + & + & + & + & + & + & + & + & + & - \\
\hline Mg P34D003 & - & + & + & - & + & + & + & + & + & + & + & + & - \\
\hline Sc HNN11516 & + & - & + & - & + & + & + & + & + & + & + & + & - \\
\hline \multicolumn{14}{|l|}{ Yeast group 2} \\
\hline Ap P01A006 & - & + & + & + & - & + & + & + & + & + & + & + & - \\
\hline \multicolumn{14}{|l|}{ Yeast group 3} \\
\hline Mp P01A016 & - & + & + & + & - & + & + & + & - & + & + & + & - \\
\hline Mp P01C004 & - & + & + & + & - & + & + & + & - & - & + & + & - \\
\hline Mc P40A002 & - & + & + & + & - & + & + & + & - & + & + & + & - \\
\hline \multicolumn{14}{|l|}{ Yeast group 4} \\
\hline Mc P34A004 & - & + & + & - & - & - & + & + & - & - & + & + & - \\
\hline Mc P34B007 & - & + & + & - & - & + & + & + & - & - & + & + & - \\
\hline \multicolumn{14}{|l|}{ Yeast group 5} \\
\hline Wa P42B001 & - & - & + & + & - & + & + & + & + & + & - & + & - \\
\hline \multicolumn{14}{|l|}{ Yeast group 6} \\
\hline Cp P45C001 & - & - & + & + & - & - & - & + & - & + & + & + & - \\
\hline \multicolumn{14}{|l|}{ Botrytis group 7} \\
\hline 101V3Dd & + & - & + & - & - & - & - & - & + & + & - & + & + \\
\hline $111 \mathrm{bb}$ & + & - & + & - & - & - & - & - & + & + & - & + & + \\
\hline $207 \mathrm{a}$ & - & - & + & - & - & - & - & - & + & + & - & + & + \\
\hline $207 \mathrm{cb}$ & - & - & + & - & - & - & - & - & + & + & - & + & + \\
\hline $407 \mathrm{cb}$ & - & - & + & - & - & - & - & - & + & + & - & + & + \\
\hline
\end{tabular}

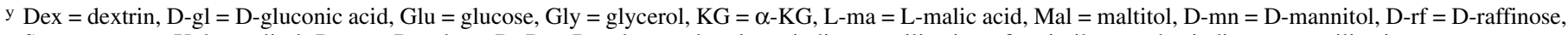
Suc $=$ sucrose, $\mathrm{Xyl}=$ xylitol, D-xy $=\mathrm{D}$-xylose, $\mathrm{D}+\mathrm{D}=\mathrm{D}$-xylose + dextrin,+ indicates utilization of assimilate, and - indicates no utilization.

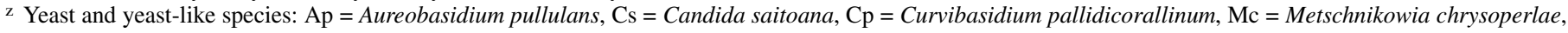
$\mathrm{Mp}=$ M. pulcherrima, $\mathrm{Mg}=$ Meyerozyma guilliermondii, Sc: Saccharomyces cerevisiae, and Wa = Wickerhamomyces anomalus . 
The yeasts used in this study showed potential as biocontrol microbes because they rapidly colonized grape berry wounds and reduced disease severity of one or more pathogen isolates on the berry without causing a significant wound response. The most promising biocontrol strains in our study were Metschnikowia spp., Meyerozyma guilliermondii, S. cerevisiae, W. anomalus, and the yeast-like fungus A. pullulans. Metschnikowia pulcherrima is wellknown for biocontrol activity against $B$. cinerea on apple (Spadaro et al. 2002; Wisniewski et al. 1991). S. cerevisiae has been widely tested as a biocontrol agent of postharvest pathogens and is commonly added to fermentations to control undesirable microorganisms (Lopes et al. 2015). Our S. cerevisiae strain, isolated from a 2014 native fermentation (X. Wang and D. Glawe, unpublished data), was an effective antagonist of $B$. cinerea in laboratory assays; however, it is not clear whether this strain is part of the native vineyard microbiota or a commercial strain that escaped from the winery. Strains of $A$. pullulans have been tested as biocontrol agents of wheat and postharvest diseases of fruit (Calvo-Garrido et al. 2014; Mari et al. 2012; Vero et al. 2009; Zhang et al. 2012). However, this organism is also known to be an opportunistic phytopathogen, causing decay on apple fruit (Heidenreich et al. 1997) and skin discoloration, degradation, and abnormalities in sweet cherry (Kim 2014). On grape, it is a member of a complex causing melting decay of Red Globe grape (Morgan and Michailides 2004). None of our isolates caused a significant rotting and collapse of the grape berry as occurs with melting disease. Although our findings indicate that $A$. pullulans is an effective broad-range inhibitor of Washington isolates of Botrytis, its ability to cause browning on grape berries and off-target symptoms on other fruit crops justifies further study of its potential impact on the quality of Washington wines.

Given the genetic diversity that occurs within beneficial native yeasts such as M. pulcherrima (Janisiewicz and Korsten 2002) and M. chrysoperlae, we think it prudent to develop and deploy yeast strains that are indigenous on our locally adapted grape cultivars. The potential effects of introduced biocontrol yeast on fermentation and wine processing is especially important because Washington wine makers rely on native yeast in vineyards for their important contributions to the aroma, flavor, and mouthfeel qualities of local premium wines. For example, $M$. pulcherrima has a role in fermentation as an inhibitor of other yeasts that impart undesirable flavors and aromas (Jolly et al. 2006) and reducing ethanol content in musts with high sugar content (J. Aplin, C. Edwards, N. Rivera, and D. Glawe, unpublished data), thereby improving wine quality. Native yeast isolates also have other highly desirable metabolic capacities such as acetic acid reduction and malolactic fermentation (Vilanova et al. 2007) that need to be considered.

Fungicide tolerance in several Washington yeast strains suggests that they could be used in combination with chemical fungicides (Lima et al. 2003, 2006). Coapplication or staggered applications of yeasts and fungicides has potential as an integrated management tool but development will require studies on compatibility, formulation, and optimization of timing. Native yeasts might also be compatible with glycolchitosan to inhibit spore germination (El-Ghaouth et al. 2000) or with plant growth regulators such as indole-3-acetic acid (Yu and Zheng 2007).

Competition for nutrients and space (niche exclusion) are generally considered to be the major mechanisms of action of most antagonistic yeasts against postharvest pathogens (Bencheqroun et al. 2007; Droby et al. 1989; El-Ghaouth et al. 1998; Haidar et al. 2016; Parafati et al. 2015; Wisniewski et al. 1991). Wound-infecting necrotrophic fungi such as $B$. cinerea require nutrients for germination and initiation of infection and, thus, are especially sensitive to niche exclusion (Janisiewicz and Korsten 2002). Yeasts are most effective as biocontrol agents when they become established on the host prior to pathogen challenge, and when they are able to rapidly colonize host tissues, as demonstrated by commercial biocontrol yeast strains (Janisiewicz and Korsten 2002). Our berry-based inhibition assay was designed to find yeasts with these traits and they showed disease suppression in many of the yeast-Botrytis interactions, suggesting nutrient or niche competition as a mechanism of biocontrol.

Similarities in metabolite oxidation and nutrient utilization among native yeasts and Botrytis isolates were isolate-dependent, and sometimes differed among individuals of the same species. The three assimilates known to be present in the berry and utilized by both yeasts and Botrytis isolates suggested that these were major nutrients for Botrytis in situ, and were limiting to the pathogen when the yeasts were present. However, additional mechanisms such as competition for minerals, water, or niche occupancy could also be important on the berry. Our berry experiments also showed that the $B$. cinerea isolates were differentially sensitive to the yeasts, suggesting that other biocontrol mechanisms may be important (Janisiewicz and Korsten 2002). For example, induced host resistance by yeasts is known in various fruit (Droby et al. 2002; Fajardo et al. 1998; Porat et al. 1999), as in the case of Candida saitoana in apple (Ippolito et al. 2000) and A. pullulans in strawberry (Adikaram et al. 2002). Interestingly, Hadwiger et al. (2015) tested seven of the same isolates used in our study and demonstrated that all of them induced phytoalexin production in pea and some of the isolates suppressed potato late blight, possibly by induced resistance. Low molecular weight metabolites such as volatile organic compounds, extracellular proteases, cell-walldegrading enzymes, iron competition, parasitism, biofilm formation, and oxidative stress can also contribute to pathogen suppression by yeast (Castoria et al. 2001; Grevesse et al. 2003; Mari et al. 2012; Parafati et al. 2015; Spadaro and Droby 2016; Wisniewski et al. 1991; Zhang et al. 2012). Our findings do not exclude antibiosis as a mechanism because antibiotic production can be dependent upon environmental and cultural conditions and interactions with the host and other microorganisms.

The differential sensitivity of our yeast suggests that Botrytis bunch rot control over a wide geographic area might require multiple yeast strains. Competition among biocontrol strains of yeast could restrict the use of yeast combinations for disease suppression (Xu and Jeger 2013; Xu et al. 2010). Improved efficacy and adaptability of a biocontrol formulation in the field (Janisiewicz and Korsten 2002) can be achieved using yeast isolates that do not compete for nutrient resources or do not antagonize each other (Woods and Bevan 1968; Young and Yagiu 1978). Therefore, we used Biolog plate studies as an initial comparison of the carbon and nitrogen utilization profiles among our yeast strains and Botrytis isolates. Both visual inspection and PCA suggested seven distinct metabolic groups. We noted that all yeasts and Botrytis isolates assimilated glucose, and observed substantial overlap in utilization among the yeast species. However, in the subset of assimilates present in grape berries, there were more differences in utilization. The yeasts have the potential to compete with each other if codeployed in the vineyard. In that regard, yeasts from groups 1 and 6 had the least degree of overlap in assimilate utilization. These data suggest that there is potential for combining specific yeast isolates in biocontrol formulations, especially if alternative biocontrol mechanisms such as iron sequestration and production of antimicrobial volatile organic compounds in M. pulcherrima (Parafati et al. 2015; Sipiczki 2006) are deployed.

This study used a popular table grape cultivar for biocontrol and colonization experiments because of its year-round availability; however, studies using wine grape cultivars such as Cabernet Sauvignon and Chardonnay, and selection and testing of single strains and strain combinations for improved biocontrol activity and wine quality, will be of interest in future studies.

\section{ACKNOWLEDGMENTS}

We thank F. Dugan and S. Lupien for isolates of Botrytis, advice on their culture, and valuable discussions of Botrytis phylogeny; and N. Muntu, 
J. Kelton, and S. Weatherly for technical assistance. Mention of trade names or commercial products in this publication is solely for the purpose of providing specific information and does not imply recommendation or endorsement by the U.S. Department of Agriculture. USDA is an equal opportunity provider and employer.

\section{LITERATURE CITED}

Adikaram, N. K., Joyce, D. C., and Terryc, L. A. 2002. Biocontrol activity and induced resistance as a possible mode of action for Aureobasidium pullulans against grey mould of strawberry fruit. Australas. Plant Pathol. 31: 223-229.

Altschul, S. F., Madden, T. L., Schäffer, A. A., Zhang, J., Zhang, Z., Miller, W., and Lipman, D. J. 1997. Gapped BLAST and PSI-BLAST: A new generation of protein 8 database search programs. Nucleic Acids Res. 25: 3389-3402.

Archbold, D. D., Hamilton-Kemp, T. R., Barth, M. M., and Langlois, B. E. 1997. Identifying natural volatile compounds that control gray mold (Botrytis cinerea) during postharvest storage of strawberry, blackberry, and grape. J. Agric. Food Chem. 45:4032-4037.

Bencheqroun, S. K., Bajji, M., Massart, S., Labhilili, M. E., Jaafari, S., and Jijakli, M. H. 2007. In vitro and in situ study of postharvest apple blue mold biocontrol by Aureobasidium pullulans: Evidence for the involvement of competition for nutrients. Postharvest Biol. Technol. 46: $128-135$

Bourret, T. B., Grove, G. G., Vandemark, G. J., Henick-Kling, T., and Glawe, D. A. 2013. Diversity and molecular determination of wild yeasts in a central Washington State vineyard. N. Am. Fungi 8:1-32.

Cabras, P., and Angioni, A. 2000. Pesticide residues in grapes, wine, and their processing products. J. Agric. Food Chem. 48:967-973.

Calvo-Garrido, C., Elmer, P. A. G., Parry, F. J., Viñas, I., Usall, J., Torres, R., Agnew, R. H., and Teixidó, N. 2014. Mode of action of a fatty acid-based natural product to control Botrytis cinerea in grapes. J. Appl. Microbiol. 116:967-979.

Campbell, C. L., and Madden, L. V. 1990. Introduction to Plant Disease Epidemiology. John Wiley \& Sons, New York, NY.

Castoria, R., De Curtis, F., Lima, G., Caputo, L., Pacifico, S., and De Cicco, V. 2001. Aureobasidium pullulans (LS-30) an antagonist of postharvest pathogens of fruits: Study on its modes of action. Postharvest Biol. Technol. 22: 7-17.

Castro, M., Kramer, K., Valdivia, L., Ortiz, S., and Castillo, A. 2003. A double-stranded RNA mycovirus confers hypovirulence-associated traits to Botrytis cinerea. FEMS Microbiol. Lett. 228:87-91.

Chanchaichaovivat, A., Ruenwongsa, P., and Panijpan, B. 2007. Screening and identification of yeast strains from fruits and vegetables: Potential for biological control of postharvest chilli anthracnose (Colletotrichum capsici). Biol. Control 42:326-335.

Conde, C., Silva, P., Fontes, N., Dias, A. C. P., Tavares, R. M., Sousa, M. J., Agasse, A., Delrot, S., and Gerós, H. 2007. Biochemical changes throughout grape berry development and fruit and wine quality. Food 1: $1-22$.

De Miccolis Angelini, R. M., Rotolo, C., Masiello, M., Gerin, D., Pollastro, S., and Faretra, F. 2014. Occurrence of fungicide resistance in populations of Botryotinia fuckeliana (Botrytis cinerea) on table grape and strawberry in southern Italy. Pest Manage. Sci. 70:1785-1796.

Droby, S., Chalutz, E., Wilson, C. L., and Wisniewski, M. 1989. Characterization of the biocontrol activity of Debaryomyces hansenii in the control of Penicillium digitatum on grapefruit. Can. J. Microbiol. 35:794-800.

Droby, S., Vinokur, V., Weiss, B., Cohen, L., Daus, A., Goldschmidt, E. E., and Porat, R. 2002. Induction of resistance to Penicillium digitatum in grapefruit by the yeast biocontrol agent Candida oleophila. Phytopathology 92: 393-399.

Dugan, F. M. 2016. Cryptic species: A leitmotif of contemporary mycology has challenges and benefits for plant pathologists. Plant Health Rev. 17: 250-253.

Dugan, F. M., Lupien, S. L., and Grove, G. G. 2002. Incidence, aggressiveness and in planta interactions of Botrytis cinerea and other filamentous fungi quiescent in grape berries and dormant buds in central Washington State. J. Phytopathol. 150:375-381.

El-Ghaouth, A., Smilanick, J. L., Brown, G. E., Ippolito, A., Wisniewski, M., and Wilson, C. L. 2000. Application of Candida saitoana and glycolchitosan for the control of postharvest diseases of apple and citrus fruit under semicommercial conditions. Plant Dis. 84:243-248.

El-Ghaouth, A., Wilson, C. L., and Wisniewski, M. 1998. Ultrastructural and cytochemical aspects of the biological control of Botrytis cinerea by Candida saitoana in apple fruit. Phytopathology 88:282-291.

Elmer, P. A. G., and Reglinski, T. 2006. Biosuppression of Botrytis cinerea in grapes. Plant Pathol. 55:155-177.
Fajardo, J. E., McCollum, T. G., McDonald, R. E., and Mayer, R. T. 1998. Differential induction of proteins in orange flavedo by biologically based elicitors and challenged by Penicillium digitatum Sacc. Biol. Control 13: $143-151$

Fernández-Ortuño, D., Chen, F., and Schnabel, G. 2012. Resistance to pyraclostrobin and boscalid in Botrytis cinerea isolates from strawberry fields in the Carolinas. Plant Dis. 96:1198-1203.

Fernández-Ortuño, D., Grabke, A., Li, X., and Schnabel, G. 2015. Independent emergence of resistance to seven chemical classes of fungicides in Botrytis cinerea. Phytopathology 105:424-432.

Ferrada, E. E., Latorre, B. A., Zoffoli, J. P., and Castillo, A. 2016. Identification and characterization of Botrytis blossom blight of Japanese plums caused by Botrytis cinerea and B. prunorum sp. nov. in Chile. Phytopathology 106:155-165.

Fleet, G. H. 2003. Yeast interactions and wine flavor. Int. J. Food Microbiol. 86:11-22.

Fugelsang, K. C., and Edwards, C. G. 2007. Wine Microbiology: Practical Applications and Procedures, 2nd ed. Springer Science and Business Media, New York.

Gerós, H., Manuela, C., and Delrot, S., eds. 2012. The Biochemistry of the Grape Berry. Bentham Science, Sharjah, UAE.

Grevesse, C., Lepoivre, P., and Jijakli, M. H. 2003. Characterization of the exoglucanase-encoding gene PaEXG2 and study of its role in the biocontrol activity of Pichia anomala strain K. Phytopathology 93:1145-1152.

Hadwiger, L. A., McDonel, H., and Glawe, D. 2015. Wild yeast strains as prospective candidates to induce resistance against potato late blight (Phytophthora infestans). Am. J. Potato Res. 92:379-386.

Haidar, R., Fermaud, M., Calvo-garrido, C., Roudet, J., and Deschamps, A. 2016. Modes of action for biological control of Botrytis cinerea by antagonistic bacteria. Phytopathol. Mediterr. 55:301-322.

Heidenreich, M. M., Corral-Garcia, M. R., Momol, E. A., and Burr, T. J. 1997. Russet of apple fruit caused by Aureobasidium pullulans and Rhodotorula glutinis. Plant Dis. 81:337-342.

Ippolito, A., El Ghaouth, A., Wilson, C. L., and Wisniewski, M. 2000. Control of postharvest decay of apple fruit by Aureobasidium pullulans and induction of defense responses. Postharvest Biol. Technol. 19:265-272.

Janisiewicz, W. J., and Korsten, L. 2002. Biological control of postharvest diseases of fruits. Annu. Rev. Phytopathol. 40:411-441.

Jolly, N. P., Augustyn, O. P. H., and Pretorius, I. S. 2006. The role and use of non-Saccharomyces yeasts in wine production. S. Afr. J. Enol. Vitic. 27: 15-39.

Keller, M., Viret, O., and Cole, F. M. 2003. Botrytis cinerea infection in grape flowers: Defense reaction, latency, and disease expression. Phytopathology 93:316-322.

Kim, Y. K. 2014. First report of a new postharvest rot in sweet cherries caused by Aureobasidium pullulans. Plant Dis. 98:424.

Kimura, M. 1980. A simple method for estimating evolutionary rate of base substitutions through comparative studies of nucleotide sequences. J. Mol. Evol. 16:111-120.

Kramer, E. K. 2015. Interactions of wild vineyard yeast with Botrytis cinerea and sensitivity to select fungicides in vitro. Master thesis, Washington State University, Pullman.

Kumar, S., Stecher, G., and Tamura, K. 2016. MEGA7: Molecular Evolutionary Genetics Analysis version 7.0 for bigger datasets. Mol. Biol. Evol. 33:1870-1874

Lima, G., De Curtis, F., Castoria, R., and De Cicco, V. 2003. Integrated control of apple postharvest pathogens and survival of biocontrol yeasts in semicommercial conditions. Eur. J. Plant Pathol. 109:341-349.

Lima, G., De Curtis, F., Piedimonte, D., Spina, A. M., and De Cicco, V. 2006. Integration of biocontrol yeast and thiabendazole protects stored apples from fungicide sensitive and resistant isolates of Botrytis cinerea. Postharvest Biol. Technol. 40:301-307.

Liu, H. M., Guo, J. H., Cheng, Y. J., Liu, P., Long, C. A., and Deng, B. X. 2010. Inhibitory activity of tea polyphenol and Hanseniaspora uvarum against Botrytis cinerea infections. Lett. Appl. Microbiol. 51:258-263.

Lopes, M. R., Klein, M. N., Ferraz, L. P., da Silva, A. C., and Kupper, K. C. 2015. Saccharomyces cerevisiae: A novel and efficient biological control agent for Colletotrichum acutatum during pre-harvest. Microbiol. Res. 175: 93-99.

Mari, M., Martini, C., Spadoni, A., Rouissi, W., and Bertolini, P. 2012. Biocontrol of apple postharvest decay by Aureobasidium pullulans. Postharvest Biol. Technol. 73:56-62.

Masih, E. I., Alie, I., and Paul, B. 2000. Can the grey mould disease of the grape-vine be controlled by yeast? FEMS Microbiol. Lett. 189:233-237.

Mavrodi, O. V., Walter, N., Elateek, S., Taylor, C. G., and Okubara, P. A. 2012. Suppression of Rhizoctonia and Pythium root rot of wheat by new strains of Pseudomonas. Biol. Control 62:93-102.

Morgan, D. P., and Michailides, T. J. 2004. First report of melting decay of 'Red Globe' grapes in California. Plant Dis. 88:1047. 
Moyer, M. M., and Grove, G. G. 2011. Botrytis Bunch Rot in Commercial Washington Grape Production: Biology and Disease Management. WSU Ext. Publ. no. FS046e. Washington State University, Pullman.

National Committee for Clinical Laboratory Standards. 1984. Performance Standards for Antimicrobial Disk Susceptibility Tests, 3rd ed. National Committee for Clinical Laboratory Standards, Villanova, PA.

Parafati, L., Vitale, A., Restuccia, C., and Cirvilleri, G. 2015. Biocontrol ability and action mechanism of food-isolated yeast strains against Botrytis cinerea causing post-harvest bunch rot of table grape. Food Microbiol. 47:85-92.

Porat, R., Lers, A., Dori, S., Cohen, L., Weiss, B., Daus, A., Wilson, C. L., and Droby, S. 1999. Induction of chitinase and $\beta$-1,3-endoglucanase proteins by UV irradiation and wounding in grapefruit peel tissue. Phytoparasitica 27: 233-238.

Rosslenbroich, H. J., and Stuebler, D. 2000. Botrytis cinerea-History of chemical control and novel fungicides for its management. Crop Prot. 19:557-561.

Sanzani, S. M., Schena, L., De Cicco, V., and Ippolito, A. 2012. Early detection of Botrytis cinerea latent infections as a tool to improve postharvest quality of table grapes. Postharvest Biol. Technol. 68:64-71.

Sipiczki, M. 2006. Metschnikowia strains isolated from botrytized grapes antagonize fungal and bacterial growth by iron depletion. Appl. Environ. Microbiol. 72:6716-6724.

Smilanick, J. L., Mansour, M. F., Mlikota Gabler, F., Margosan, D. A., and Hashim-Buckey, J. 2010. Control of postharvest gray mold of table grapes in the San Joaquin Valley of California by fungicides applied during the growing season. Plant Dis. 94:250-257.

Spadaro, D., and Droby, S. 2016. Development of biocontrol products for postharvest diseases of fruit: The importance of elucidating the mechanisms of action of yeast antagonists. Trends Food Sci. Technol. 47:39-49.

Spadaro, D., Vola, R., Piano, S., and Gullino, M. L. 2002. Mechanisms of action and efficacy of four isolates of the yeast Metschnikowia pulcherrima active against postharvest pathogens on apples. Postharvest Biol. Technol. 24:123-134.

Staats, M., van Baarlen, P., and van Kan, J. A. 2005. Molecular phylogeny of the plant pathogenic genus Botrytis and the evolution of host specificity. Mol. Biol. Evol. 22:333-346.

Steel, C. C., Blackman, J. W., and Schmidtke, L. M. 2013. Grapevine bunch rots: Impacts on wine composition, quality, and potential procedures for the removal of wine faults. J. Agric. Food Chem. 61:5189-5206.

Stevens, R. B., ed. 1981. Mycology Guidebook. University of Washington Press, Seattle.

Van Rensburg, P., and Pretorius, I. S. 2000. Enzymes in winemaking: Harnessing natural catalysts for efficient biotransformations. A review. S. Afr. J. Enol. Vitic. 21:52-73.

Vero, S., Garmendia, G., Gonzalez, M. B., Garat, M. F., and Wisniewski, M. 2009. Aureobasidium pullulans as a biocontrol agent of postharvest pathogens of apples in Uruguay. Biocontrol Sci. Technol. 19:1033-1049.

Vilanova, M., Ugliano, M., Varela, C., Siebert, T., Pretorius, I. S., and Henschke, P. A. 2007. Assimilable nitrogen utilisation and production of volatile and non-volatile compounds in chemically defined medium by Saccharomyces cerevisiae wine yeasts. Appl. Microb. Biotechnol. 77:145-157.

Walker, A. S. 2016. Diversity within and between species of Botrytis. Pages 91-125 in: Botrytis-The Fungus, the Pathogen and its Management in Agricultural Systems. S. Fillinger and Y. Elad, eds. Springer, New York.

WASS. 2003. Washington Grape Report, January 27, 2003. Washington Agricultural Statistics Service (WASS), Olympia.

White, T. J., Bruns, T., Lee, S. J. W. T., and Taylor, J. W. 1990. Amplification and direct sequencing of fungal ribosomal RNA genes for phylogenetics. Pages 315-322 in: PCR Protocols: A Guide to Methods and Applications. M. Innis, D. Gelfand, J. Sninsky, and T. White, eds. Academic Press, San Diego, CA.

Wilcox, W. F., Mahaffee, W., and Gubler, W. D. 2015. Botrytis bunch rot and blight. Pages 39-45 in: Compendium of Grape Diseases, Disorders, and Pests. W. F. Wilcox, W. D. Gubler, and J. K. Uyemoto, eds. American Phytopathological Society, St. Paul, MN.

Wisniewski, M., Biles, C., Droby, S., McLaughlin, R., Wilson, C., and Chalultz, E. 1991. Mode of action of the postharvest biocontrol yeast Pichia guilliermondii. I. Characterization of attachment to Botrytis cinerea. Physiol. Mol. Plant Pathol. 39:245-258.

Woods, D. R., and Bevan, E. A. 1968. Studies on the nature of the killer factor produced by Saccharomyces cerevisiae. J. Gen. Microbiol. 51:115-126.

Wu, M. D., Zhang, L., Li, G. Q., Jiang, D. H., Hou, M. S., and Huang, H. C. 2007. Hypovirulence and double-stranded RNA in Botrytis cinerea. Phytopathology 97:1590-1599.

Xu, X. M., and Jeger, M. J. 2013. Combined use of two biocontrol agents with different biocontrol mechanisms most likely results in less than expected efficacy in controlling foliar pathogens under fluctuating conditions: A modeling study. Phytopathology 103:108-116.

Xu, X. M., Salama, N., Jeffries, P., and Jeger, M. J. 2010. Numerical studies of biocontrol efficacies of foliar plant pathogens in relation to the characteristics of a biocontrol agent. Phytopathology 100:814-821.

Young, T. W., and Yagiu, M. 1978. A comparison of the killer character in different yeasts and its classification. Antonie Leeuwenhoek 44:59-77.

Yu, T., and Zheng, X. D. 2007. An integrated strategy to control postharvest blue and grey mould rots of apple fruit by combining biocontrol yeast with gibberellic acid. J. Food Sci. Technol. 42:977-984.

Zhang, D., Spadaro, D., Valente, S., Garibaldi, A., and Gullino, M. L. 2012. Cloning, characterization, expression and antifungal activity of an alkaline serine protease of Aureobasidium pullulans PL5 involved in the biological control of postharvest pathogens. Int. J. Food Microbiol. 153:453-464.

Zhao, L., Chanon, A. M., Chattopadhyay, N., Dami, I. E., and Blakeslee, J. J. 2016. Quantification of carbohydrates in grape tissues using capillary zone electrophoresis. Front. Plant Sci. 7:818.

Zhimo, V. Y., Bhutia, D. D., Saha, J., and Panja, B. 2014. Exploitation of yeasts as an alternative strategy to control postharvest diseases of fruits-A review. World Appl. Sci. J. 31:785-793. 